\title{
Taxonomic reconsideration of Disporum luzoniense (Liliaceae s.I.) using flavonoid characters
}

\author{
Y. Saito ${ }^{1,2}$, T. Iwashina ${ }^{1,2}$, C.-I Peng ${ }^{3}$, G. Kokubugata ${ }^{1,2}$
}

Key words

Disporopsis

Disporum

Liliaceae s.I.

Philippines

Taiwan

taxonomy

\begin{abstract}
Phytochemical characters of the plants that have been treated as Disporum luzoniense (Merrill \& Merrit 1910) or Disporopsis fuscopicta (Jessop 1979) in the Philippines were compared with those of Disporum kawakami and Disporopsis fuscopicta in Taiwan. The present phytochemical study revealed that Disporum kawakamii had luteolin, apigenin and chrysoeriol as free state, while these flavonoids were not detected in the Philippine plant and Disporopsis fuscopicta from Taiwan. Moreover, flavone O-glycosides were isolated from Disporum kawakamii, while flavone $C$-glycoside was isolated from the Philippine plant and Disporopsis fuscopicta from Taiwan. In conclusion, the present study suggests that the Philippine plant is chemotaxonomically related to Disporopsis and this agrees with the taxonomic treatment of Jessop (1979).
\end{abstract}

Published on 30 October 2009

\section{INTRODUCTION}

The genus Disporum Salisb. (Liliaceae s.I.; Colchicaceae sensu, APG II 2003) consist of 22 species primarily distributed in the temperate zone of eastern Asia (Kawano \& Takasu 2004). On the other hand, the genus Disporopsis Hance (Liliaceae s.I.; Convallariaceae, APG II 2003) consists of 6 species that are primarily distributed in eastern Asia (Liang \& Tamura 2000). In 1910 Merrill (Merrill \& Merritt 1910) described Disporum luzoniense based on a type specimen collected from Benguet Province, Luzon, the Philippines (E.D. Merrill 6619, deposited in US). Thereafter, Jessop (1979) identified the Benguet plant as Disporopsis fuscopicta Hance based on morphological characters. His taxonomic treatment was taken up by Kumar \& Brandham (1980) and Hara (1988).

Flavonoid compounds based on a fifteen-carbon skeleton consist of two phenyl rings (A- and B-rings) connected by a threecarbon bridge (C-ring). In most cases, the flavonoids are present as glycosides in flowers, leaves, stems or roots. They were divided into several classes, i.e., flavones, flavonols, flavanones, anthocyanins, etc. Numerous kinds of flavonoids have been found in plants by the combination of additional hydroxyl, methoxyl, methyl and/or glycosyl groups. At the present, more than 7000 kinds of flavonoids have been reported as natural products (Andersen \& Markham 2006). These flavonoids have frequently been used as chemotaxonomic markers (e.g. Iwashina et al. 1995, Yamazaki et al. 2007).

The aim of the present study is to assess the taxonomic status of the plant previously labelled as Disporum luzoniense from the Philippines by comparing the phytochemical characters with morphological and cytological observation and to compare this plant with specimens labelled as Disporum and Disporopsis from Taiwan.

\footnotetext{
Tokyo University of Agriculture and Technology, 3-5-8 Saiwai-cho, Fuchu, Tokyo, 183-8509 Japan.

2 Tsukuba Botanical Garden, Department of Botany, National Museum of Nature and Science, 4 Amakubo, Tsukuba, Ibaraki, 305-0005 Japan.

${ }^{3}$ Herbarium (HAST), Biodiversity Research Center, Academia Sinica, Taipei, 115 Taiwan.
}

\section{MATERIAL AND METHODS}

\section{Plant materials}

Plant materials from the experimental greenhouse of Tsukuba Botanical Garden, National Museum of Nature and Science were used for morphological, phytochemical and cytological study. Voucher specimens are deposited in the herbarium of the National Museum of Nature and Science (TNS).

\section{Morphological characters}

The following morphological characters of the specimens were observed in this study: presence/absence of corona inside of perianth and presence/absence of rhizomes.

One of two plants collected from Taiwan was morphologically identified as Disporum kawakamii Hayata in having an umbel type of inflorescence with few flowers (Fig. 1a), no corona inside the perianth and very thin or no rhizomes at all (Fig. 1d, Ying 2000); and another was identified as Disporopsis fuscopicta Hance var. arisanensis (Hayata) S.S.Ying in having an axillary inflorescence (Fig. 1c), well-developed rhizomes (Fig. 1f), and presence of a corona inside the perianth (Fig. 2, Ying 2000).

The floral and rhizome morphologies of the plant from the Philippines were similar to those of Disporopsis fuscopicta var. arisanensis, and were also consistent with the description of Disporum luzoniense.

\section{Chromosome study}

Root tips were harvested, pretreated in $2 \mathrm{mM}$ 8-hydroxyquinoline at $20^{\circ} \mathrm{C}$ for $2 \mathrm{~h}$, and fixed in acetic ethanol $(1: 3)$ at $4{ }^{\circ} \mathrm{C}$ for $2 \mathrm{~h}$. The fixed root tips were macerated in $2: 1$ mixture of $1 \mathrm{~N}$ hydrochloric acid and $45 \%$ acetic acid at $60{ }^{\circ} \mathrm{C}$ for 10 seconds. Somatic chromosomes at mitotic metaphase were stained in $2 \%$ aceto-orcein at $20^{\circ} \mathrm{C}$ for $2 \mathrm{~h}$, and spread by the standard squash method.

\section{Flavonoid extraction and isolation}

Fresh leaves of Disporum kawakamii (25 g), Disporum luzoniense from the Philippines (129 g) and Disporopsis fuscopicta var. arisanensis $(45 \mathrm{~g})$ were extracted with methanol. The flavonoids were isolated by preparative paper chromatography

(c) 2009 Nationaal Herbarium Nederland

You are free to share - to copy, distribute and transmit the work, under the following conditions:

Attribution: $\quad$ You must attribute the work in the manner specified by the author or licensor (but not in any way that suggests that they endorse you or your use of the work)

Non-commercia: 

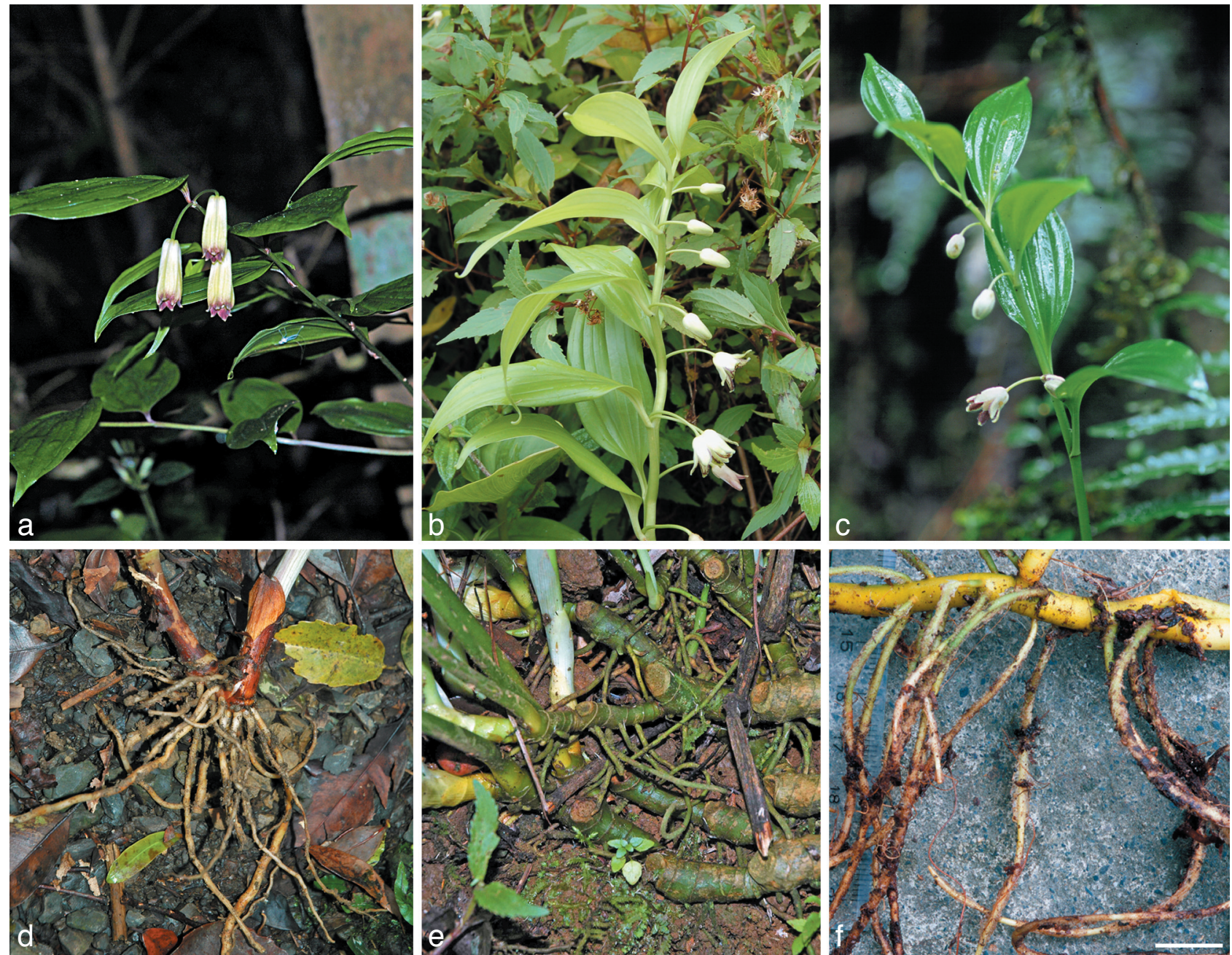

Fig. 1 Plant materials. a, d. Disporum kawakamii; b, e. Philippine plant; c, f. Disporopsis fuscopicta var. arisanensis. - Scale bar $=3 \mathrm{~cm}$.

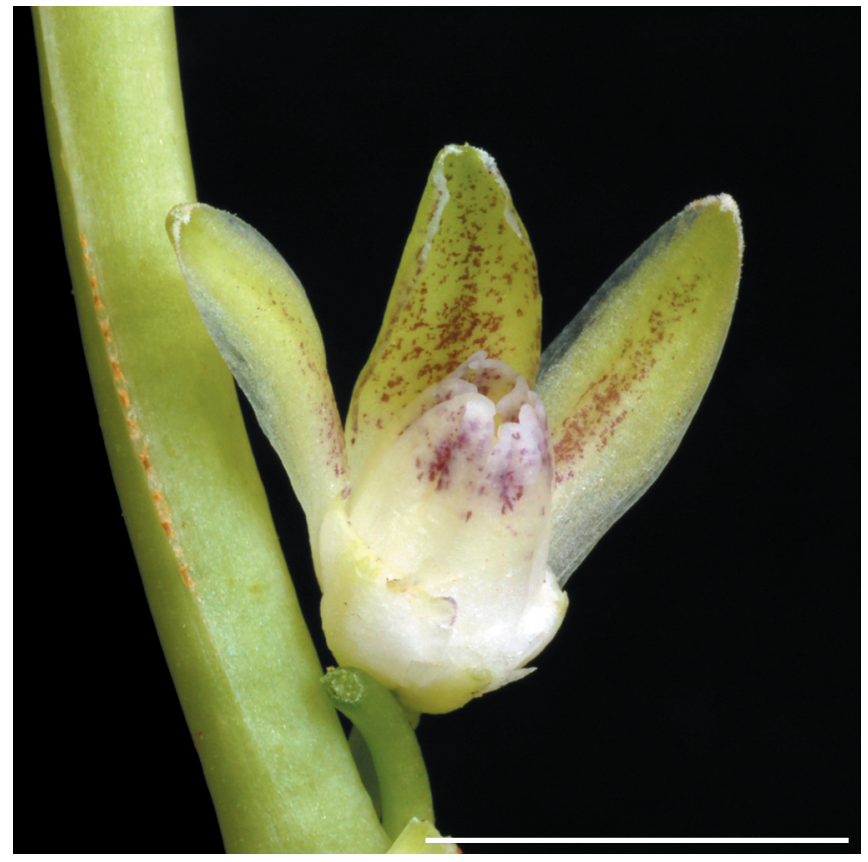

Fig. 2 Corona inside of perianth of Philippine plant. - Scale bar $=1 \mathrm{~cm}$.

using solvent systems: BAW $\left(n-\mathrm{BuOH} / \mathrm{HOAc} / \mathrm{H}_{2} \mathrm{O}=4: 1: 5\right.$, upper phase), $15 \%$ HOAc (glycosides) or $50 \%$ HOAc (aglycones) and then BEW ( $\left.n-\mathrm{BuOH} / \mathrm{EtOH} / \mathrm{H}_{2} \mathrm{O}=4: 1: 2.2\right)$. Their isolated flavonoids were purified by Sephadex LH-20 column chromatography using solvent system: $70 \% \mathrm{MeOH}$.

\section{HPLC and PC survey of crude extracts}

The $\mathrm{MeOH}$ extracts were surveyed for flavonoid composition by Shimadzu HPLC systems (Shimadzu Co., Japan) using Pegasil ODS (I.D. $=6.0 \times 150 \mathrm{~mm}$ (Senshu Scientific Co., Japan)) at a flow rate of $1.0 \mathrm{~mL} \mathrm{~min}^{-1}$, injection: $10 \mu \mathrm{l}$, detection wavelength of $190-700 \mathrm{~nm}$, and eluents of $\mathrm{MeCN} / \mathrm{H}_{2} \mathrm{O} / \mathrm{H}_{3} \mathrm{PO}_{4}(35: 65: 0.2)$ (Solvent I) for crude extracts and aglycones and $\mathrm{MeCN} / \mathrm{H}_{2} \mathrm{O}$ / $\mathrm{H}_{3} \mathrm{PO}_{4}(22: 78: 0.2)$ (Solvent II) for glycosides. Two-dimensional paper chromatography (2D-PC) was performed using solvent systems: BAW (1st) and $15 \%$ HOAc (2nd).

\section{Identification of flavonoids}

The isolated compounds were identified by UV spectral survey according to Mabry et al. (1970), LC-MS, acid hydrolysis (in $12 \%$ aq. $\mathrm{HCl}, 100{ }^{\circ} \mathrm{C}, 30 \mathrm{~min}$ ), and direct TLC and HPLC comparisons with authentic specimens. TLC, UV, LC-MS and HPLC data of the isolated compounds were as follows.

Luteolin (1). TLC: $R_{f} 0.88$ (BAW), 0.03 (15\% HOAc), 0.91 (BEW); UV - dark purple and UV/NH 3 - bright yellow. HPLC: retention time (Rt) 5.73 min (Solvent I). UV: $\lambda_{\text {max }}(\mathrm{nm}) \mathrm{MeOH}$ 255, 266sh, 349; +NaOMe 268, 326, 403 (inc.); + $\mathrm{AlCl}_{3}$ 272, 422; $+\mathrm{AlCl}_{3} / \mathrm{HCl} 257,273$ sh, 296, 359, 385sh; +NaOAc 267, 396; $+\mathrm{NaOAc} / \mathrm{H}_{3} \mathrm{BO}_{3}$ 262, 373. LC-MS: m/z $285[\mathrm{M}-\mathrm{H}]$ ].

Luteolin 7-O-glucoside (4). TLC: $R_{f} 0.34$ (BAW), 0.07 (15\% HOAc), 0.54 (BEW); UV - dark purple and UV/NH yellow. HPLC: Rt 6.01 min (Solvent II). UV: $\lambda_{\max }(\mathrm{nm}) \mathrm{MeOH}$ 256, 268sh, 351; +NaOMe 268, 394 (inc.); + $\mathrm{AlCl}_{3} 272,417$; $+\mathrm{AlCl}_{3} / \mathrm{HCl} 262$, 274sh, 293, 357, 383sh; +NaOAc 260, 405; $+\mathrm{NaOAc} / \mathrm{H}_{3} \mathrm{BO}_{3}$ 258, 372. LC-MS: m/z 447 [M-H]', 285 [Mglucosyl-H]'. 

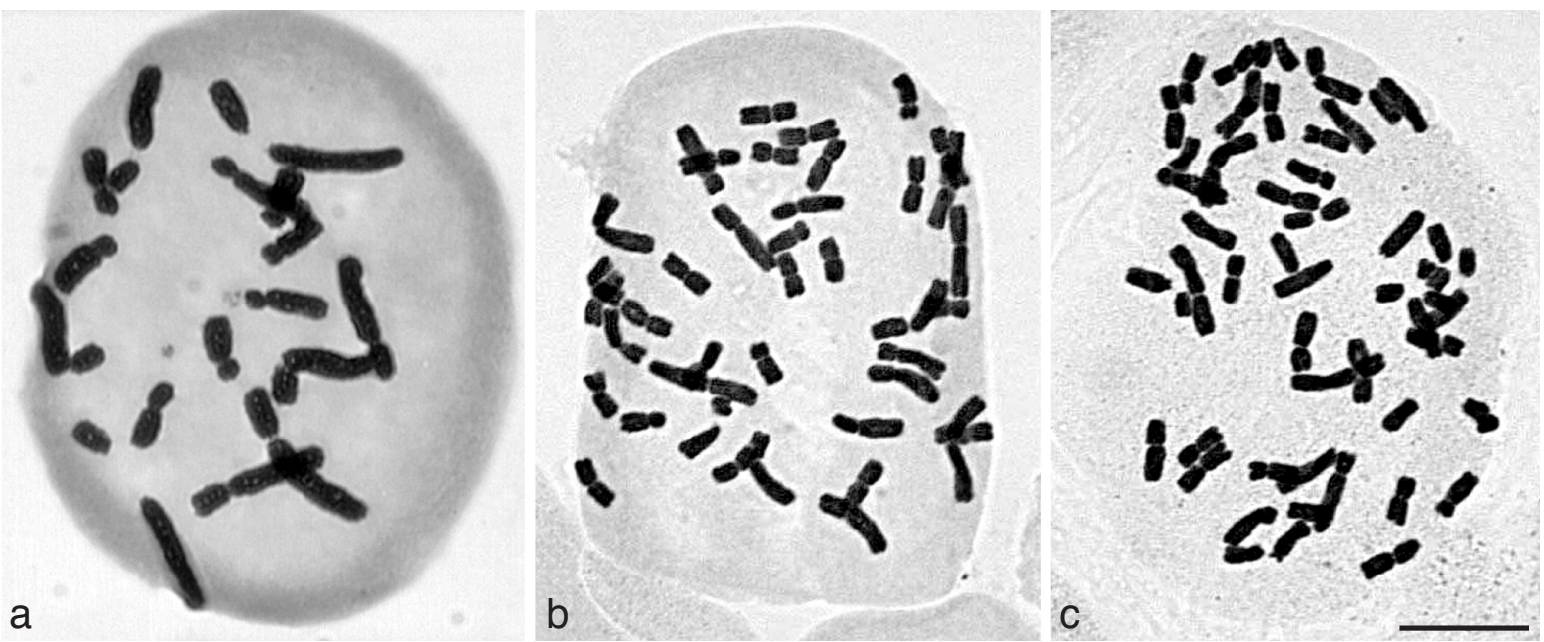

Fig. 3 Chromosomes stained with aceto-orcein at mitotic metaphase of plants investigated. a. Disporum kawakamii; b. Philippine plant; c. Disporopsis fuscopicta var. arisanensis. - Scale bar $=10 \mu \mathrm{m}$.

Luteolin 4'-O-glucoside (5). TLC: $R_{f} 0.61$ (BAW), 0.08 (15\% HOAc), 0.66 (BEW); UV and UV/NH $\mathrm{NH}_{3}$ - dark purple. HPLC: Rt 8.90 min (Solvent II). UV: $\lambda_{\text {max }}(\mathrm{nm}) \mathrm{MeOH} 269,335 ;+\mathrm{NaOMe}$ 267, 375 (dec.); + $\mathrm{AlCl}_{3} 277,293 \mathrm{sh}, 354,380 \mathrm{sh} ;+\mathrm{AlCl}_{3} / \mathrm{HCl} 277$, 293sh, 351, 375sh; +NaOAc 269, 374; +NaOAc/ $\mathrm{H}_{3} \mathrm{BO}_{3} 270$, 341. LC-MS: $m / z 447$ [M-H]', 285 [M-glucosyl-H]'.

Luteolin 7-O-diglucoside (6). TLC: $R_{f} 0.61$ (BAW), 0.08 (15\% HOAc), 0.66 (BEW); UV - dark purple and UV/NH - bright yellow. HPLC: Rt 4.49 min (Solvent II). UV: $\lambda_{\max }(\mathrm{nm}) \mathrm{MeOH} 255$, 268,$348 ;+\mathrm{NaOMe} 268,392$ (inc.); $+\mathrm{AlCl}_{3} 273,425 ;+\mathrm{AlCl}_{3} / \mathrm{HCl}$ 265 , 275sh, 295, 360, 385; +NaOAc 261, 405; +NaOAc/ $\mathrm{H}_{3} \mathrm{BO}_{3}$ 259, 373. LC-MS: $m / z 609$ [M-H]'.

Luteolin 7-O-rhamnosylglucoside (7). TLC: $R_{f} 0.36$ (BAW), 0.11 (15\% HOAc), 0.46 (BEW); UV - dark purple and UV/NH - bright yellow. HPLC: Rt 5.50 min (Solvent II). UV: $\lambda_{\max }(\mathrm{nm})$ $\mathrm{MeOH}$ 255, 265sh, 349; +NaOMe 268, 390 (inc.); $+\mathrm{AlCl}_{3} 272$, 425; + $\mathrm{AlCl}_{3} / \mathrm{HCl} 262,274,296,361,385 \mathrm{sh}$; +NaOAc 260, 405; $+\mathrm{NaOAc} / \mathrm{H}_{3} \mathrm{BO}_{3}$ 259, 374. LC-MS: $m / z 593$ [M-H].

Apigenin 6- $C$-hexoside-8- $C$-pentoside or 6-C-pentoside-8- $C$ hexoside (8). TLC: $R_{f} 0.21$ (BAW), 0.41 (15\% HOAc), 0.24 (BEW); UV - dark purple and UV/NH $\mathrm{N}_{3}$ - orange. HPLC: Rt 4.50 min (Solvent II). UV: $\lambda_{\max }(\mathrm{nm}) \mathrm{MeOH} 273,333$; +NaOMe 283, 334, 402 (inc.); $+\mathrm{AlCl}_{3} 281,306,351,380 ;+\mathrm{AlCl}_{3} / \mathrm{HCl} 280,304$, 347,$380 ;+\mathrm{NaOAc} 283,395 ;+\mathrm{NaOAc} / \mathrm{H}_{3} \mathrm{BO}_{3} 285,319,354$, 415. LC-MS: $m / z 563$ [M-H].

\section{RESULTS AND DISCUSSION}

\section{Chromosome numbers}

The plant of Disporopsis fuscopicta var. arisanensis and the plant labelled as Disporum luzoniense had the same chromosome number of $2 n=40$, which agrees with the findings of Chang \& Hsu (1974) and Kumar \& Brandham (1980) (Table 1 , Fig. $3 b, c)$. The chromosome number corresponds with the basic chromosome number of $\mathrm{x}=20$ in the genus Disporopsis (Darlington \& Wylie 1955, Chang \& Hsu 1974, Hong \& Zhu 1990). On the other hand, Disporum kawakamii had a somatic chromosome number of $2 \mathrm{n}=16$ (Table1, Fig. 3a). This number agrees with the findings of Chao et al. (1963), Chang \& Hsu (1974) and Tamura et al. (1992).

Previously Kumar \& Brandham (1980) detected the chromosome number of $2 n=40$ for a plant collected from the type locality of Disporum luzoniense, and then cytotaxonomically supported Jessop (1979). Also the present cytological investigation upholds Jessop's taxonomic treatment (1979) and also agrees with the findings of Kumar \& Brandham (1980).

\section{Phytochemical analysis and conclusion}

Five major flavonoids were isolated from Disporum kawakamii (Table 2). They were completely identified as luteolin (1), luteolin 7-O-glucoside (4), luteolin 4'-O-glucoside (5), luteolin 7-O-diglucoside (6) and luteolin 7-O-rhamnosylglucoside (7).

Table 1 Comparison of morphological and cytological characters of plant materials studied.

\begin{tabular}{|c|c|c|c|c|}
\hline Species & Inflorescence & Rhizome & Corona & Chrom. no. (2n) \\
\hline Disporum kawakamii (Hsinchu, Taiwan; GK 5207) & terminal & absent & absent & 16 \\
\hline $\begin{array}{l}\text { Disporum luzoniense sensu Merrill/ } \\
\text { Disporopsis fuscopicta sensu Jessop (Luzon, Philippines; YS 346) }\end{array}$ & axillary & present & present & 40 \\
\hline Disporopsis fuscopicta var. arisanensis (Ilan, Taiwan, YS 392) & axillary & present & present & 40 \\
\hline
\end{tabular}

Table 2 Flavonoid characters.

\begin{tabular}{|c|c|c|c|c|c|c|c|c|}
\hline \multirow[t]{3}{*}{ Species } & \multicolumn{3}{|c|}{ Aglycones } & \multicolumn{5}{|c|}{ Glycosides } \\
\hline & \multirow[b]{2}{*}{1} & \multirow[b]{2}{*}{2} & \multirow[b]{2}{*}{3} & \multicolumn{4}{|c|}{ O-glycosides } & \multirow{2}{*}{$\begin{array}{c}\text { C-glycoside } \\
8\end{array}$} \\
\hline & & & & 4 & 5 & 6 & 7 & \\
\hline Disporum kawakamii & + & + & + & + & + & + & + & - \\
\hline Disporum Iuzoniense/Disporopsis fuscopicta (Philippines) & - & - & - & - & - & - & - & + \\
\hline Disporopsis fuscopicta var. arisanensis & - & - & - & - & - & - & - & + \\
\hline
\end{tabular}

$\mathbf{1}$ = luteolin; $\mathbf{2}$ = apigenin; $\mathbf{3}$ = chrysoeriol; $\mathbf{4}$ = luteolin 7-O-glucoside; $\mathbf{5}$ = luteolin 4'-O-glucoside; $\mathbf{6}$ = luteolin 7-O-diglucoside; 7 = luteolin 7-O-rhamnosylglucoside; 8 = apigenin 6-C-hexoside-8C-pentoside or 6-C-pentoside-8-C-hexoside. 
Furthermore two minor flavonoids were inferred as apigenin (2) and chrysoeriol (3) by HPLC comparisons with authentic samples, but the two minor flavonoids could not be completely identified for lack of enough samples.

Previously a chemotaxonomic study has been done on three Asian Disporum species, e.g., D. calcaratum, D. cantoniense and $D$. sessile, and the three species revealed that their main flavonoids were luteolin glycosides (Williams et al. 1993). In the present survey, main flavonoids were also four luteolin glycosides (4, 5, 6 and 7) in Disporum kawakamii following Williams et al. (1993). However, out of five major flavonoids detected (1, 4, 5, 6 and 7), luteolin 7-O-rhamnosylglucoside (7) in $D$. kawakamii was different from that of luteolin 7-O-rutinoside (i.e. 7-O-rhamnosyl-(1 $\rightarrow 6)$-glucoside) in the three Disporum species (Williams et al. 1993). Further phytochemical study is necessary for clarifying chemotaxonomic relationships in the genus Disporum.

On the other hand, only one flavone C-glycoside (8) was isolated from the Philippine plant and Disporopsis fuscopicta var. arisanensis in Taiwan (Table 2), but any flavone O-glycosides and flavone aglycones were not isolated from the two plants differing from that of Disporum kawakamii.

The present phytochemical analysis reveals that the flavonoid composition of the plant labelled as Disporum luzoniense is completely consistent with Disporopsis fuscopicta var. arisanensis but distinctly different from those of Disporum kawakamii and the three Disporum species reported by Williams et al. (1993). In conclusion, the phytochemical study suggests that the Philippine plant that was previously identified as Disporum Iuzoniense is actually related to Disporopsis. Our phytochemical study result agrees with the taxonomic study of Jessop (1979) and Kumar \& Brandham (1980).

Acknowledgements We sincerely thank Chien-I Huang, Hebarium (HAST), Biodiversity Research Center, Academia Sinica, Taiwan and Ray Ong (in Manila) for field assistance. This study was supported in part by a Research Fellowships of the Japan Society for the Promotion of Science for Young Scientists of JSPS (YS), and the project 'Integration of Systematics and Molecular Phylogenetics in All Groups of Organisms' of the National Science Museum (GK).

\section{REFERENCES}

Andersen ØM, Markham KR. 2006. Flavonoids. Chemistry, Biochemistry and Applications. Taylor, Francis, New York.

Angiosperm Phylogeny Group (APG II). 2003. An update of the Angiosperm Phylogeny Group classification for the orders and families of flowering plants: APG II. Botanical Journal of the Linnean Society 141: 399-436.

Chang H-J, Hsu CC. 1974. A cytotaxonomical study on some Formosan Liliaceae. Taiwania 19: 58-74.

Chao C-Y, Chung TI, Hu WWL. 1963. A cytotaxonomic study of the Disporum of Taiwan. Botanical Bulletin of Academia Sinica 4: 80-89.

Darlington CD, Wylie AP. 1955. Chromosome atlas of flowering plants. Allen, Unwin, London.

Hara H. 1988. A revision of the Asiatic species of the genus Disporum (Liliaceae). The University Musuem, the University of Tokyo, Bulletin 31: 163 209.

Hong D-Y, Zhu XY. 1990. Report on karyotypes of 6 species in 4 genera of Polygonateae from China. Acta Phytotaxonomica Sinica 28: 199-206.

Iwashina T, Matsumoto S, Nishida M, Nakaike T. 1995. New and rare flavonol glycosides from Asplenium trichomanes-ramosum as stable chemotaxonomic markers. Biochemical Systematics and Ecology 23: 283-290.

Jessop JP. 1979. Liliaceae-1. Flora Malesiana, Ser. I, Vol. 9: 189-235.

Kawano S, Takasu H. 2004. In: Kawano S (ed), Life history monographs of Japanese plants. Vol. 1: 25-32. Hokkaido University Press, Sapporo.

Kumar V, Brandham PE. 1980. Cytotaxonomy of Disporum luzoniense (Liliaceae-Polygonatae). Kew Bulletin 35: 493-497.

Liang S-J, Tamura MN. 2000. Disporopsis. In: Wu Z-Y, Raven PH (eds), Flora of China 24: 232-234. Science Press, Beijing, Missouri Botanical Garden Press, St. Louis.

Mabry TJ, Markham KR, Thomas MB. 1970. The systematic identification of flavonoids. Springer, Berlin.

Merrill ED, Merritt ML. 1910. Flora of Mount Pulog. Philippine Journal of Science. Section C, Botany 5: 287-401.

Tamura NM, Utech FH, Kawano S. 1992. Biosystematic studies on the genus Disporum (Liliaceae-Polygonateae) IV. Karyotypes analysis of some Asiatic and North American taxa with special references to their systematic status. Plant Species Biology 7: 103-120.

Yamazaki K, Iwashina T, Kitajima J, Gamou Y, Yoshida A, Tannowa T. 2007. External and internal flavonoids from Madagascarian Uncarina species (Pedaliaceae). Biochemical Systematics and Ecology 35: 743-749.

Ying S-S. 2000. Liliaceae. In: Editorial Committee Flora Taiwan (eds), Flora of Taiwan, 2nd ed., 5: 44-47. Taipei, Taiwan.

Williams CA, Richardson J, Greenham J, Eagles J. 1993. Correlations between leaf flavonoids, taxonomy and plant geography in the genus Disporum. Phytochemistry 34: 197-203. 